\title{
Territorialização da política pública do PAA e o caso da AACEPPAMO, município de Óbidos, Amazônia Paraense
}

\author{
Márcio Júnior Benassuly Barros \\ Universidade Federal do Oeste do Pará - Santarém - Pará - Brasil \\ ORCID: https://orcid.org/0000-0001-5764-5692 \\ Elzamili Lima Brito \\ Universidade Federal do Oeste do Pará - Santarém - Pará - Brasil \\ ORCID: https://orcid.org/0000-0003-4181-1726 \\ Francilene Sales da Conceição \\ Universidade Federal do Oeste do Pará - Santarém - Pará - Brasil \\ ORCID: https://orcid.org/0000-0002-3401-326X \\ Raoni Fernandes Azerêdo \\ Universidade Federal do Oeste do Pará - Alenquer - Pará - Brasil \\ ORCID: https://orcid.org/0000-0002-4088-7430
}

\begin{abstract}
Resumo
A presente pesquisa tem como objetivo analisar a experiência da Associação Agroextrativista dos Pescadores e Pescadoras do Município de Óbidos (ACEPPAMO) com o Programa de Aquisição de Alimentos (PAA) em Óbidos, Pará. Os procedimentos metodológicos utilizados foram: revisão bibliográfica do tema, levantamento documental em instituições públicas, entrevista com representantes de entidades envolvidas no PAA, trabalho de campo e elaboração de cartografia temática. Os principais resultados indicam que a execução desta política pública tem contribuído para a melhoria da renda dos pequenos agricultores/pescadores associados à ACEPPAMO, além de contribuir com a segurança alimentar dos beneficiários atendidos com a distribuição do pescado no município de Óbidos. Consideramos que esta pesquisa se justifica pela necessidade de aprofundar conhecimentos, em especial na Amazônia, sobre programas e políticas públicas de fomento ao cooperativismo e associativismo no meio rural, que a exemplo do PAA, tem gerado renda às populações de camadas historicamente desfavorecidas economicamente/socialmente e retirado milhares de pessoas da situação de miséria e fome no Brasil.
\end{abstract}

Palavras-chave: Política Pública. PAA. Segurança alimentar. Pesca. Óbidos. 
Territorialização da política pública do PAA e o caso da AACEPPAMO, município de Óbidos, Amazônia Paraense

\title{
Territorialization of PAA public policy and the case of AACEPPAMO, Óbidos region, in Amazonian Pará
}

\begin{abstract}
The present research aims at analyzing the experience of the Agro-extrativist Association of fisherman and fisherwomen in the Óbidos region (ACEPPAMO) with the Program of Food Acquisition (PFA) in Óbidos, Pará. The methodological procedures used were the following: bibliographical revision of the theme, documental survey in public institutions, interviews with representatives of the engaged entities in the Program, field work and elaboration of the thematic cartography. The main results show that carrying out this public policy has contributed with the improvement of the income of minor peasants and fishermen members of ACEPPAMO, in addition to contributing with the food security of those benefitting from the distribution of fish in the Óbidos region. The research is justified by the need to deepen knowledge, especially in the Amazon, about programs and public policies foster to cooperativism and associativism in the rural environment, which like the PAA, has generated income for historically economically / socially underprivileged populations and removed thousands people from the situation of misery and hunger in Brazil.
\end{abstract}

Keywords: Public policy. PAA. food security. Fishing. Óbidos.

\section{Territorialización de la política pública del PAA y el caso de la AACEPPAMO, municipio de Óbidos, Amazônia Pará}

\section{Resumen}

La presente investigación tiene como objetivo analizar la experiencia de la Asociación Agroectractivista de los Pescadores del Municipio de Óbidos (ACEPPAMO) con el Programa de Adquisición de Alimentos (PAA) en Óbidos, Pará. Los procedimientos metodológicos utilizados fueron: revisión bibliográfica sobre el tema, recopilación documental en instituciones públicas, entrevista con representantes de entidades involucradas al PAA, trabajo de campo y elaboración de cartografía temática. Los principales resultados indican que la ejecución de esta política pública ha contribuido a la mejora de la renta de los pequeños agricultores/pescadores asociados a la ACEPPAMO, además de contribuir con la seguridad alimentaria de los beneficiarios asistidos con la distribución del pescado en el municipio de Óbidos. Consideramos que esta investigación se justifica por la necesidad de profundizar conocimientos, en especial en la Amazonia, sobre programas y políticas públicas de fomento al cooperativismo y al asociativismo en el medio rural, que en el ejemplo del PAA, ha generado ingresos para las poblaciones de capas históricamente desfavorecidas económicamente / socialmente y rescatado a miles de personas de la situación de miseria y hambre en Brasil.

Palabras clave: Políticas Pública. PAA. Seguridad alimentaria. Pesca. Óbidos.

\section{Introdução}

Um dos grandes entraves enfrentados pelos agricultores familiares/pescadores artesanais brasileiros, principalmente os de pequeno porte, têm sido a comercialização de seus produtos. O Programa de Aquisição de Alimentos (PAA) é parte da estratégia de um programa maior, o Fome Zero ( $F Z$ ), que tem como finalidade implementar: a) ações de segurança alimentar e 
nutricional; b) a inclusão social e econômica de agricultores familiares e pescadores artesanais na economia local.

Nesse contexto, o PAA se consolidou como um instrumento de luta contra a fome. Representa, do ponto de vista da segurança alimentar e nutricional o êxito do Estado brasileiro na aquisição de alimentos ao longo dos anos, bem como, o fortalecimento da agricultura familiar. Este programa foi responsável pela melhoria da renda dos agricultores, valorização da produção local e de sua diversificação, atraindo a atenção internacional, justamente pela consistência e a eficácia no contexto socioeconômico e por introduzir mudanças territoriais e espaciais.

Assim, este trabalho objetiva compreender a experiência da Associação Agroextrativista dos Pescadores e Pescadoras do Município de Óbidos (ACEPPAMO) com o Programa de Aquisição de Alimentos (PAA) em Óbidos, Pará.

A metodologia aplicada está amparada em uma pesquisa quantitativa e qualitativa, o que consistiu em: 1) Pesquisa Bibliográfica: Foi realizada revisão teórica-conceitual referente às políticas públicas e agricultura familiar; 2) Pesquisa Documental: Foram analisados documentos e dados quantitativos da Companhia Nacional de Abastecimento (CONAB) disponibilizados no site da instituição; 3) Pesquisa de Campo: Ocorreu no município de Óbidos-PA com sujeitos associados, famílias beneficiárias e instituições que participam das ações do PAA. O instrumento para a coletas de dados se deu por meio de entrevistas semiestruturadas (perguntas abertas e fechadas), com uso do questionário roteiro, aplicados aos representantes do Centro Pastoral da Criança de Óbidos, à diretoria da AACEPAMO, aos pescadores associados à AACEPAMO e as famílias assistidas pela Pastoral da Criança de Óbidos. Foram levantadas as seguintes questões acerca da AACEPAMO: dados pessoais, origem, características, funcionalidade, administração, produção, distribuição, famílias/comunidades atendidas e as lutas e resistências enfrentadas.

O recorte espacial onde se desenvolveu a pesquisa foi o município de Óbidos (Oeste do Estado do Pará, situado na mesorregião do Baixo Amazonas (Mapa 1), Amazônia brasileira) que possui uma população estimada em 2016 de 50.596 habitantes, segundo o Instituto Brasileiro de Geografia e Estatística (IBGE), e que tem na agricultura familiar e pesca artesanal suas principais atividades econômicas desenvolvidas. A escolha de Óbidos, deve-se ao fato de ser o único município do Baixo Amazonas que por meio da associação, a AACEPAMO, participou com maior regularidade durante os anos de 2010 a 2016 do Programa de Aquisição de Alimentos na modalidade de Compra com Doação Simultânea (CDS), com protagonismo e dinamismo de agricultores e pescadores do município, que viram no programa a possibilidade concreta de agregar valor ao pescado, dinamizar a economia local e fortalecer o tecido associativo. 
Mapa 1 - Mapa de localização do município de Óbidos, PA.

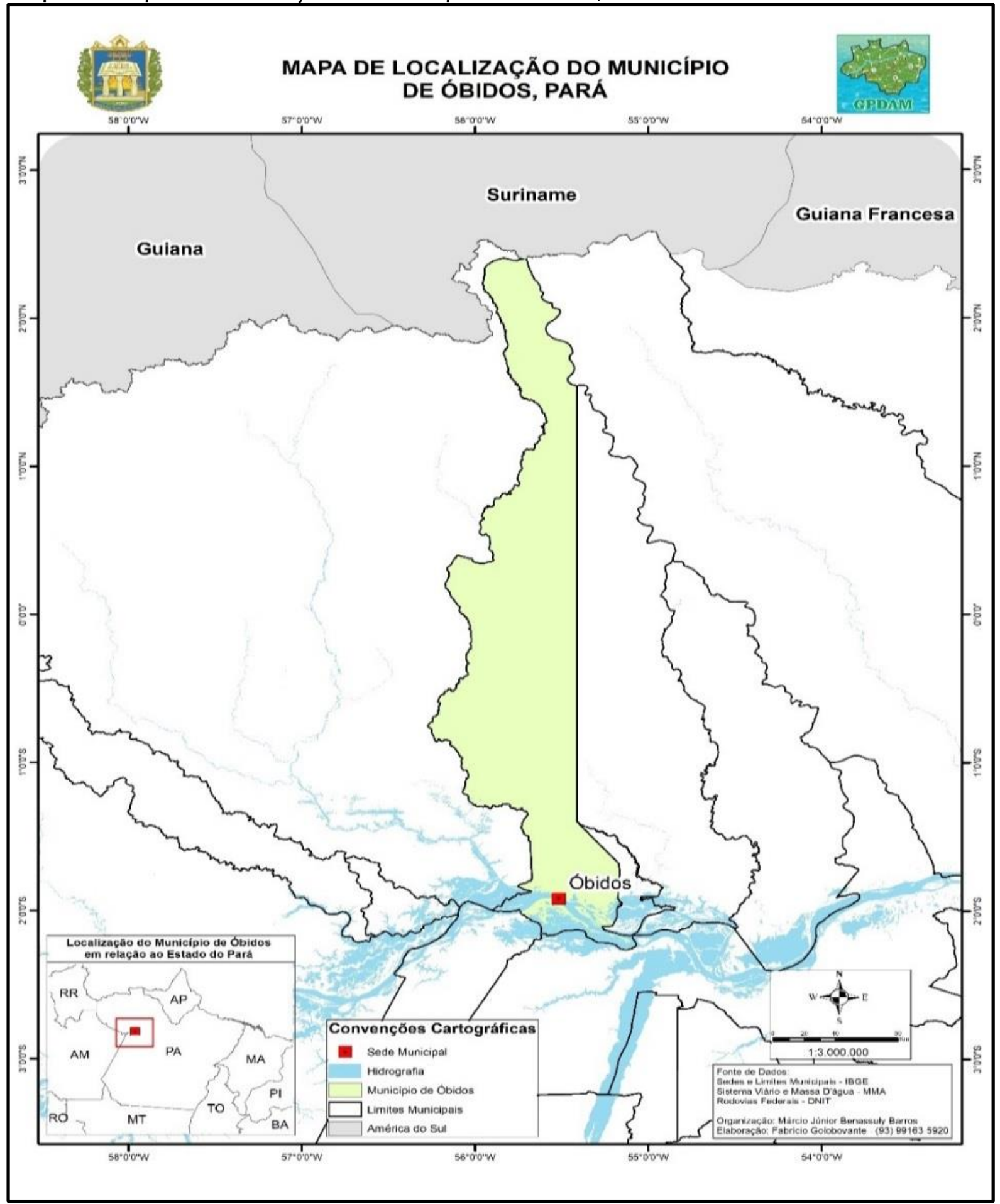

Fonte: Organizado pelos próprios autores, 2019.

Vale salientar que os programas de fomento à produção e comercialização rural da agricultura familiar são recentes no cenário social do Brasil, e ainda bastante incipientes, especialmente em se tratando da região amazônica. Portanto, pesquisas como esta, justificam-se pela imperatividade de realizarem análises que esclareçam e aprofundem conhecimentos sobre a aplicação, efetividade e impactos territoriais destes no meio rural, que a exemplo do PAA, tem gerado renda às 
populações de camadas desfavorecidas economicamente e retirado milhares de pessoas da situação de miséria e fome no Brasil, além de fortalecer o associativismo/cooperativismo.

\section{Territorialização das políticas públicas no território brasileiro: a execução do PAA pela CONAB}

Discutir territorialização pressupõe antes analisar o conceito de território. Em Da desterritorialização á multiterritorialidade, Rogério Haesbaert (2005) afirma que "desde a origem, o território nasce com uma dupla conotação, material e simbólica, pois etnologicamente aparece tão próximo de terra - territorium quanto de térreo - terrritor (terror, aterrorizar), ou seja, tem a ver com dominação (jurídico - política) (HAESBAERT, 2005, p.6774). Para o autor:

Território, assim, em qualquer acepção, tem a ver com poder, mas não apenas ao tradicional "poder político". Ele diz respeito tanto ao poder no sentido mais concreto, de dominação, quanto ao poder no sentido mais simbólico, de apropriação (HAESBAERT, 2005, p.6774).

Raffestin (1993) faz uma diferenciação entre espaço e território quando afirma que "espaço e território não são termos equivalentes. [...] É essencial compreender bem que o espaço é anterior ao território. O território se forma a partir do espaço, é o resultado de uma ação conduzida por um ator sintagmático" (RAFFESTIN, 1993, p. 143). Ainda para ele, "ao se apropriar de um espaço, concreta ou abstratamente (por exemplo, pela representação), o ator "territorializa" o espaço" (RAFFESTIN, 1993, p. 143).

A territorialização passa a ser entendida como a ação que os atores exercem sobre os territórios. Pierre Teisserenc (2010) em Ambientalização e Territorialização: situando o debate no contexto da Amazônia brasileira, faz uma reflexão sobre a palavra territorialização.

A palavra territorialização já sugere, antes de tudo, um processo que envolve atores, ações nas quais eles se engajam, relações múltiplas e cotidianas na forma de jogos de alianças ou de redes, práticas objetivas e subjetivas em referência a escalas espaciais diferentes. Por meio de suas relações, ações e práticas, esses atores juntos desenvolvem formas de apropriação, materiais e simbólicas, do espaço que comportam dimensões econômicas, políticas e culturais. São dimensões que caracterizam sua territorialidade. (TEISSERENC, 2010, p. 165).

Territorialização como analisado por Teisserenc (2010) é um processo onde os atores desenvolvem ações em territórios nos quais possuem influências de diversas naturezas. Segundo este autor, "disso se coloca uma definição de territorialização como uma produção social que, de acordo com Rogério Haesbaert, é o resultado de "uma hibridação entre sociedade e natureza, entre política, economia e cultura" [...]" (TEISSERENC, 2010, p. 164).

Neste sentido, sob a ótica da perspectiva territorial, a política pública do PAA é relativamente recente no Brasil, resultado de um longo processo de discussão e construção envolvendo movimentos e organizações sociais da agricultura familiar e instituições governamentais (MULLER; SILVA; SCHNEIDER, 2012). 
Por sua vez Schmitt (2005), assim como para Koth (2019), argumentam que o PAA é uma política pública agrícola de segurança alimentar e nutricional criada em 2003 como uma ação estrutural no contexto do Programa Fome Zero. Para os autores, o programa fortalece a agricultura familiar com relação à comercialização da produção, garantindo às populações vulneráveis (indígenas, quilombolas, atingidos por barragens e populações em situação emergencial), o direito constitucional a uma alimentação de qualidade.

No entanto, Salgado et al (2017) em publicação sobre a avaliação do PAA nas regiões brasileiras, a pesquisa constatou que a taxa de cobertura desta política nas regiões ainda é desigual, com frágil presença do programa nas regiões Norte e Nordeste.

Consideramos que o PAA, conjuntamente com o Programa Nacional de Alimentação Escolar (PNAE) fazem parte de uma estratégia governamental basilar para a estruturação da agricultura familiar no enfrentamento à carência alimentar e nutricional ainda presente no Brasil. Este último programa, que tem na lei 11.947, de 16 de junho de 2009, estabelece que os municípios devem obrigatoriamente adquirirem um percentual mínimo de 30\% dos recursos do Fundo Nacional de Desenvolvimento da Educação (FNDE) para a compra de produtos da agricultura familiar.

Sambuichi (2014) enfatiza que estas políticas foram determinante para a criação de um imenso mercado institucional de compras por parte da União, estados e municípios por alimentos produzidos por pequenos agricultores no Brasil.

Na sequência passamos a abordar a execução pela CONAB do PAA. A

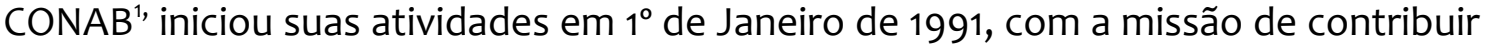
com a regularidade do abastecimento e garantia de renda ao produtor rural. Agrega-se ainda a essa instituição, a participação na formulação e execução de políticas agrícolas de abastecimento, além de possuir uma diversidade ímpar no fornecimento de informações e conhecimentos do setor agrícola. Suas ações são fortemente conectadas com o rural, com a produção, com os setores econômico e produtivo de todos os perfis e portes, inclusive, muitas vezes alcançando onde nenhum órgão público consegue chegar (BRASIL, 2017).

$\mathrm{Na}$ economia em que a agricultura tem papel muito importante, existe uma preocupação em estabelecer políticas de sustentação de renda para o setor. Nesse sentido, a CONAB tem capilaridade de atuação em todo território nacional, acompanhando a trajetória da produção agrícola, desde o planejamento do plantio até chegar à mesa do consumidor, por meio de suas 27 superintendências regionais, localizadas nos diversos Estados da federação, e vinculadas a elas.

A atuação da CONAB no PAA teve início desde a territorialização das ações no território brasileiro do programa em 2003, dentro da Diretoria de Política Agrícola e Informações (DIPAI) e da Superintendência de Suporte à Agricultura Familiar (SUPAF). Esta é composta pela Gerência de Acompanhamento de Controle das Ações da Agricultura Familiar (GECAF), Gerência de Programação Operacional

1 Empresa pública, vinculada ao Ministério da Agricultura, Pecuária e Abastecimento (MAPA), criada por decreto presidencial e autorizada pela Lei $n^{\circ} 8.029$, de 12 de abril de 1990. 
da Agricultura Familiar (GEPAF) e Gerência de Apoio aos negócios e a Comercialização de Empreendimentos Familiares (GENOC), localizadas na sede da CONAB em Brasília-DF.

Cabe salientar que o PAA atua por meio de cinco modalidades, todas voltadas para a agricultura familiar com ações territorializadas pela CONAB nos estados e municípios brasileiros, através de um Termo de Cooperação Técnica, sendo definidas pelo GGPAA por meio de resoluções específicas. Os recursos são disponibilizados pelo Ministério do MDSA e SEAD. Sendo que para a participação do agricultor em algumas das modalidades é preciso que este esteja vinculado a uma organização associativa ou cooperativa.

Para participarem do programa, os agricultores precisam obter gratuitamente junto às instituições oficialmente autorizadas, a exemplo das entidades oficiais de Assistência Técnica e Extensão Rural (EMATER) ou as Federações e Confederações de Agricultores, por meio de seus sindicatos, a Declaração de Aptidão ao Pronaf (DAP), principal documento que vai identificar o trabalhador/agricultor/da pesca artesanal, extrativistas que praticam a atividade de maneira ecologicamente sustentável, piscicultor, comunidades quilombolas, silvicultores e povos indígenas, enquadrados como agricultor familiar pessoa física, e/ou suas formas associativas organizadas em pessoas jurídicas, que conferem a estes o direito a acessar políticas públicas e programas de crédito, como o Programa de Agricultura Familiar (PRONAF), o PAA, O Programa Nacional de Alimentação Escolar (PNAE), Habitação Rural, entre outras.

É importante esclarecer que a DAP é destinada para a unidade familiar. Portanto, compreende o conjunto da família (marido ou companheira, esposa ou companheiro e filhos) e eventuais agregados(as). Os pescadores que desejarem obter o documento devem ter a carteira de pescador profissional atualizada. 0 programa tem como princípio incentivar as comunidades participantes a direcionarem o seu olhar para os resultados esperados, vislumbrando um retorno financeiro ao estímulo à permanência do trabalhador/pescador rural na sua região.

\subsection{Tipologias de modalidades de operacionalização do PAA pela CONAB}

Em 2003, no seu ano de implementação, a demanda do PAA ficou mais concentrada em alguns Estados do Centro-Oeste e Estados da região do Nordeste, sendo que os recursos empenhados foram apenas de $\mathrm{R} \$ 82,5$ milhões naquele ano. Quanto às demandas das modalidades executadas, a Compra Direta e a Compra Antecipada da Agricultura Familiar foram a que apresentaram menor nível de dificuldade de acesso por parte dos agricultores (BRASIL, 2012).

No ano de 2004, começaram as operações do PAA em três modalidades, sendo: Compra Direta da Agricultura Familiar (CDAF), Compra Antecipada Especial da Agricultura Familiar com Doação Simultânea (CAEAF-CPR-Doação) e a Compra Antecipada Especial da Agricultura Familiar com Formação de Estoque (CAEAFEstoque). Posteriormente, foram incluídas no rol de operações a aquisição de sementes, operacionalizado pela CONAB e o PAA-leite, operacionalizado nos estados da região Nordeste e no Estado de Minas Gerais. 
O Quadro 1 a seguir, descreve as modalidades em que a CONAB possui destaque nas modalidades de atuação, seus objetivos, por quem o programa é operacionalizado e os valores dos recursos aplicados.

Quadro 1- Execução do PAA pela CONAB.

\begin{tabular}{|c|c|c|c|}
\hline MODALIDADES & OBJETIVOS & QUEM OPERA & FONTE DE RECURSOS \\
\hline $\begin{array}{l}\text { Compra da Agricultura } \\
\text { Familiar com Doação } \\
\text { Simultânea - CPR } \\
\text { Doação }\end{array}$ & $\begin{array}{l}\text { Aquisição de alimentos } \\
\text { de Organizações } \\
\text { Fornecedoras } \\
\text { constituídas } \\
\text { Beneficiários } \\
\text { Fornecedores, com } \\
\text { objetivo de atender as } \\
\text { demandas locais de } \\
\text { suplementação } \\
\text { alimentar, promovendo } \\
\text { o Direito Humano à } \\
\text { Alimentação Adequada. }\end{array}$ & $\begin{array}{l}\text { Operacionalizada } \\
\text { pela CONAB e } \\
\text { recebe recursos do } \\
\text { MDSA. }\end{array}$ & $\begin{array}{l}\text { Até R\$ } 8.000,00 \text { (oito mil } \\
\text { reais) por unidade } \\
\text { familiar/ano civil. E até R\$ } \\
2.000 .000,00 \text { (dois milhões } \\
\text { de reais) por organização } \\
\text { fornecedora por ano civil, } \\
\text { sendo a primeira operação } \\
\text { limitada a } \\
\begin{array}{l}\text { 300.000,00 (trezentos mil } \\
\text { reais). }\end{array}\end{array}$ \\
\hline $\begin{array}{l}\text { Formação de Estoque } \\
\text { pela Agricultura } \\
\text { Familiar-CPR Estoque }\end{array}$ & $\begin{array}{l}\text { Apoiar financeiramente } \\
\text { a constituição de } \\
\text { estoques de alimentos } \\
\text { por organizações da } \\
\text { agricultura familiar, } \\
\text { para posterior } \\
\text { comercialização e } \\
\text { devolução dos recursos } \\
\text { financeiros ao Poder } \\
\text { Público. }\end{array}$ & $\begin{array}{l}\text { Operacionalizada } \\
\text { pela CONAB e } \\
\text { recebe recursos } \\
\text { advindos da SEAD. }\end{array}$ & $\begin{array}{l}\text { O valor da produção própria, } \\
\text { não pode ultrapassar R\$ } \\
8.000,00 \text { (oito mil reais) } \\
\text { /unidade familiar/ano. Das } \\
\text { Organizações Fornecedoras: } \\
\text { até R\$ 1.500.000,00 (um } \\
\text { milhão e quinhentos mil } \\
\text { reais), sendo a primeira } \\
\text { operação limitada a } \\
\text { R\$ 300.000,00 (trezentos } \\
\text { mil reais). }\end{array}$ \\
\hline $\begin{array}{l}\text { CDAF-Compra Direta } \\
\text { da Agricultura Familiar }\end{array}$ & $\begin{array}{l}\text { Sustentar preços de } \\
\text { uma pauta específica de } \\
\text { produtos definida pelo } \\
\text { GGPAA, para a } \\
\text { constituição } r \text { de } \\
\text { estoques públicos } \\
\text { desses produtos e o } \\
\text { atendimento de } \\
\text { demandas de } \\
\text { programas de acesso à } \\
\text { alimentação. }\end{array}$ & $\begin{array}{l}\text { Operacionalizada } \\
\text { pela CONAB e } \\
\text { recebe recursos } \\
\text { advindos da SEAD } \\
\text { E MDSA. }\end{array}$ & $\begin{array}{l}\text { Permite a aquisição de } \\
\text { produtos até o limite anual } \\
\text { de } \mathrm{R} \$ 8.000,00 \text { (oito mil } \\
\text { reais) por unidade familiar, } \\
\text { sendor acessada } \\
\text { individualmente. }\end{array}$ \\
\hline PAA - Leite & $\begin{array}{l}\text { Contribuir com o } \\
\text { aumento do consumo } \\
\text { de leite pelas famílias } \\
\text { que se encontram em } \\
\text { situação de insegurança } \\
\text { alimentar e nutricional e } \\
\text { também incentivar a } \\
\text { produção leiteira dos } \\
\text { agricultores familiares. }\end{array}$ & $\begin{array}{l}\text { Operacionalizada } \\
\text { pelos estados do } \\
\text { Nordeste e Minas } \\
\text { Gerais. }\end{array}$ & $\begin{array}{l}\text { Recebe } 85 \% \text { dos recursos do } \\
\text { MDSA e o restante dos } \\
\text { próprios estados. O valor } \\
\text { comercializado } \\
\text { agricultor/semestre é } \mathrm{R} \$ \\
4.000,00 .\end{array}$ \\
\hline Aquisição de Sementes & $\begin{array}{lr}\text { Comprar } & \text { sementes, } \\
\text { mudas } & \text { e } \text { outros } \\
\text { materiais } & \text { propagativos } \\
\text { para } & \text { alimentação }\end{array}$ & \begin{tabular}{l}
\multicolumn{2}{l}{ Operacionalizada } \\
pela CONAB e \\
recebe recursos \\
advindos
\end{tabular} & $\begin{array}{l}\text { Permite aquisição de até } \mathrm{R} \$ \\
16.000,00 \text { (Dezesseis mil } \\
\text { reais) por unidade } \\
\text { familiar/ano; e até } \mathrm{R} \$\end{array}$ \\
\hline
\end{tabular}




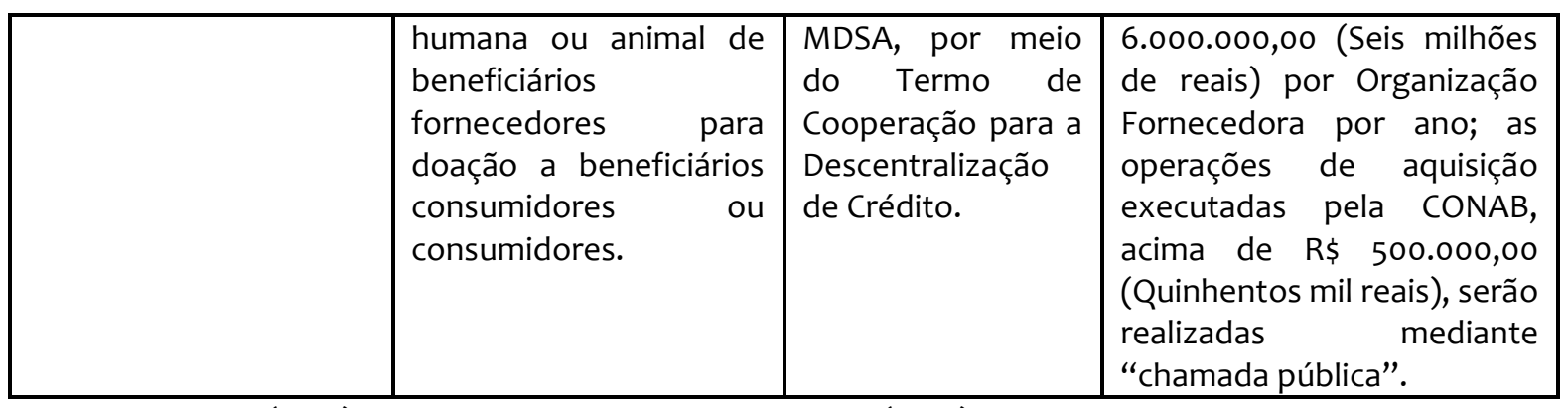

Fonte: CONAB (2017). Organizado pelos próprios autores (2019).

A seguir, apresentam-se mais detalhadamente as principais características das modalidades do PAA.

a) CDS-Doação Simultânea: Modalidade é executada pela CONAB e o produtor pode ter acesso ao programa por meio de cooperativas e outras organizações formalmente constituídas como pessoa jurídica de direito privado que detenham a Declaração de Aptidão ao PRONAF - DAP Jurídica. O limite de aquisição é de até R\$ 8.000,00 (oito mil reais) por unidade familiar/ano e de até $\mathrm{R} \$ \mathbf{2 . 0 0 0 . 0 0 0 , 0 0}$ (dois milhões de reais) por organização fornecedora por ano civil.

b) CRP/Estoque: Modalidade executada pela CONAB, onde o produtor pode ter acesso por meio de cooperativas ou associações que detenham a Declaração de Aptidão ao Pronaf-DAP Jurídica. O limite por beneficiários fornecedores não pode ultrapassar $\mathrm{R} \$ \mathbf{8 . 0 0 0 , 0 0}$ (oito mil reais)/unidade familiar/ano civil não sendo cumulativo com as demais modalidades do PAA. E das organizações fornecedoras até R\$1.500.000,00 (um milhão e quinhentos mil reais), para participantes com personalidade jurídica, a primeira operação é limitada a $\mathrm{R} \$$ 300.000,00 (trezentos mil reais).

c) CDAF: Modalidade executada pela CONAB, cujos participantes são agricultores enquadrados no Pronaf, organizados, preferencialmente, em grupos formais (cooperativas e associações) ou informais, como os povos e comunidades tradicionais, extrativistas, quilombolas, famílias atingidas por barragens, trabalhadores rurais, comunidades indígenas e agricultores familiares em condições especiais (autorizados pela CONAB), com limite por agricultor/ano de $\mathrm{R} \$ \mathbf{8 . 0 0 0 , 0 0}$ (oito mil reais), não sendo cumulativo com outras modalidades.

d) PAA-leite: Modalidade executada apenas na região Nordeste e estado de Minas Gerais, com recursos do MDSA e também dos estados. O limite agricultor/semestre é $\mathrm{R} \$ 4.000,00$. O produtor pode ter acesso por meio de cooperativas e associações ou individualmente.

e) PAA-Aquisição de Sementes: modalidade executada pela CONAB, e permite as organizações fornecedoras que detenham a DAP Jurídica: (cooperativas ou associações) aquisição de até $\mathrm{R} \$ 16.000,00$ (Dezesseis mil reais) por unidade familiar/ano civil e até $\mathrm{R} \$ \mathbf{6 . 0 0 0 . 0 0 0 , 0 0}$ (Seis milhões de reais) por organização fornecedora por ano civil. As operações de aquisição executadas pela CONAB, acima de $\mathrm{R} \$$ 500.000,00 (Quinhentos mil reais), serão realizadas mediante chamada pública.

\subsection{Distribuição do PAA pela CONAB no território brasiliero}

O PAA completou 15 anos de operação, em 02 de julho de 2018. É relevante destacar alguns aspectos do que já foi realizado pelo programa durante este 
período. Segundo estudos da CONAB (2014), sobre a evolução da implementação do PAA, verifica-se um aumento dos recursos aplicados e do público beneficiado até o ano de 2015, depois desse ano os recursos aplicados foram diminuídos (BRASIL, 2017).

No ano de 2014, o PAA atuou em 2.729 (48,9\%) municípios de um total de 5.570 municípios brasileiros e tem atuado como um mecanismo de sustentação de preços em nível local, produzindo renda e inclusão no mercado da agricultura familiar e promovendo o desenvolvimento local e regional. Os principais sujeitos atendidos pelo PAA são os consumidores em situação de insegurança alimentar e nutricional, atendidos por programas sociais locais (HONDA; GOMES; CABRAL, 2016).

Segundo Honda, Gomes, Cabral (2016), em 2014, a CONAB possibilitou a comercialização de 178.603 toneladas de alimentos produzidos por 51.228 famílias agricultoras, pertencentes aos grupos do PRONAF no Brasil, por intermédio dos seguintes instrumentos de aquisição de alimentos do Governo Federal: Compra Direta da Agricultura Familiar (CDAF), Compra da Agricultura Familiar com Doação Simultânea (CPR-Doação) e Formação de Estoque pela Agricultura Familiar (CPMEstoque). Foram atendidas 3.968 unidades recebedoras (instituições cadastradas) em que 11.460.634 pessoas em estado de insegurança alimentar foram beneficiadas (BRASIL, 2014), bem como grupos indígenas selecionados, acampamentos da reforma agrária, comunidades quilombolas e atingidos por barragens (GUARECHI, 2010).

Nesse contexto, apresenta-se a evolução dos recursos por regiões, aplicados pela Secretaria Especial de Agricultura Familiar e do Desenvolvimento Agrário (SEAD) e pelo Ministério do Desenvolvimento Social e Agrário (MDSA) na aquisição de produtos no período de sete anos de PAA (Tabela 1). Consoante os dados exibidos na tabela seguinte, pode-se verificar que nesse período foram investidos mais de 1 bilhão de reais.

Tabela 1 - Evolução dos recursos SEAD/MDSA aplicados na aquisição de produtos do PAA de 2010- 2016.

\begin{tabular}{|c|c|c|c|c|c|c|}
\hline \multirow[b]{2}{*}{ ANO } & \multicolumn{5}{|c|}{ Valor (R\$) } & \multirow[b]{2}{*}{ TOTAL } \\
\hline & $\begin{array}{c}\text { Centro- } \\
\text { Oeste }\end{array}$ & Nordeste & Norte & Sudeste & Sul & \\
\hline 2010 & 21.400 .943 & 121.858 .906 & 28.348 .787 & 79.151 .714 & 128.975 .115 & 379.735 .466 \\
\hline 2011 & 32.025 .103 & 153.674 .198 & 29.386 .137 & 111.741 .509 & 124.209 .257 & 451.036 .204 \\
\hline 2012 & 43.282 .942 & $154 \cdot 904 \cdot 344$ & 36.045 .217 & 131.776 .716 & 220.557 .912 & 586.567 .131 \\
\hline 2013 & 24.075 .247 & 66.487 .273 & 22.938 .796 & 67.812 .376 & 43.203 .433 & 224.517 .124 \\
\hline 2014 & 31.155 .531 & 79.992 .989 & 37.860 .917 & 128.709 .065 & 60.286 .440 & 338.004 .942 \\
\hline 2015 & 29.589 .161 & 92.549 .198 & 33.399 .258 & 77.902 .561 & 54.075 .037 & 287.515 .216 \\
\hline 2016 & 17.187 .827 & 88.470 .743 & 27.873 .958 & 41.313 .390 & 22.730 .799 & $197 \cdot 576.718$ \\
\hline TOTAL & 198.716 .754 & 757.937 .651 & 215.853 .070 & 638.407 .331 & 654.037 .993 & 1.979 .860 .867 \\
\hline
\end{tabular}

Fonte: CONAB (2017). Organizado pelos próprios autores (2019). 
A partir da análise da tabela acima, verifica-se que os estados mais beneficiados nesse período, estão nas regiões Sul e Nordeste, onde há mais investimentos de recursos. Isso significa dizer que, essas regiões são contempladas por meio da formulação de políticas públicas voltadas para a execução do PAA. A aplicabilidade dos recursos destinados ao PAA (Gráfico 1) e que são incorporadas nas agendas estão distribuídas de acordo com cada região do Brasil.

Gráfico 1 - Aplicação de recurso do PAA nas regiões brasileiras nos anos de 20102016.

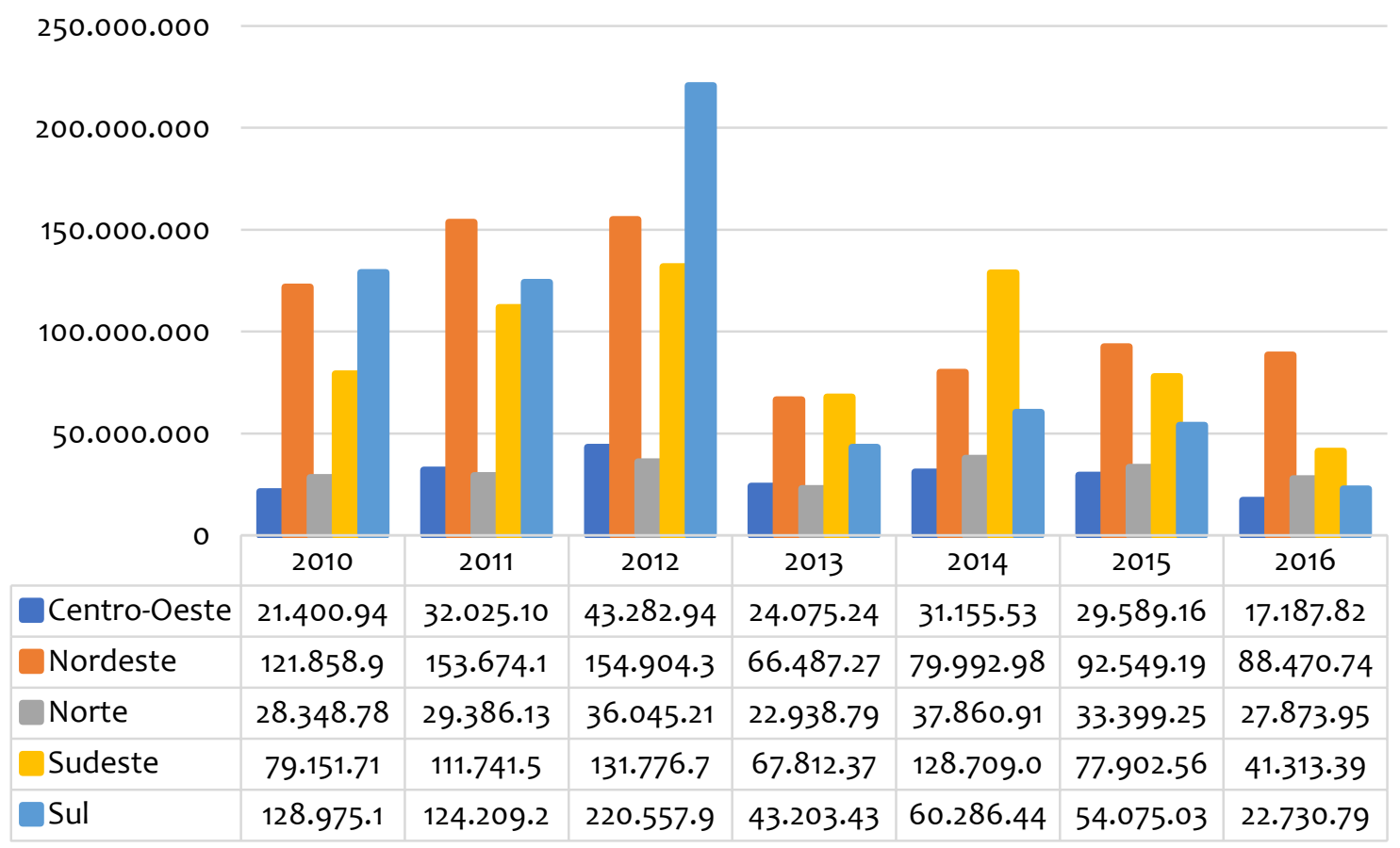

Valores investidos por ano

Centro-Oeste Nordeste Norte Sudeste Sul

Fonte: CONAB (2017). Organizado pelos próprios autores (2019).

O quantitativo correspondente ao período de 2010 a 2016 de cada região apontado no Gráfico 2, pode-se observar que nos anos de 2011 e 2012 foram os que mais houveram investimento e captação de recursos nos programas do PAA em todas as regiões brasileiras, sendo lideradas pelo Nordeste no ranking de captação de recursos, seguido pelo Sul e Sudeste. Assim, esses dados que se destacaram, equivalentes aos anos supracitados e suas respectivas regiões, reforçam a hipótese de que a política pública aplicada nessas duas regiões por meio do PAA provocaram alguns avanços e reestruturações na economia regional.

É importante apontar ainda, que em 2013 houve uma queda abrupta da arrecadação de recursos em todas as regiões brasileiras, voltando a ter uma sucinta elevação no ano de 2014. De 2014 a 2016, a captação de recursos se mantém em queda, finalizando o período com o Nordeste liderando o ranking e se destacando como a região que obteve maior resultado no valor investido, seguido pelo Sudeste, Sul, Norte e o Centro-Oeste. 
Os resultados apontados desse programa, segundo estudos realizados pelo MDS, os agricultores familiares participantes alcançaram avanços na sua renda mensal, com preços superiores comparado aos agricultores não participantes, gerando grande satisfação com os preços estabelecidos com seus produtos (VEIGA; OLIVEIRA; BENTES, 2007).

A guisa de conclusão, em 2016 foram formalizadas 845 propostas de participação em todo o Brasil, sendo 825 propostas da modalidade de Compra com Doação Simultânea (CDS) e 20 da modalidade Formação de Estoque. Conforme a Tabela 02 é possível afirmar que a região Nordeste foi a mais atuante e a que mais se destacou no território brasileiro, alçando o correspondente aos 403 projetos.

Tabela 2 - Distribuição dos projetos do PAA formalizados por região em 2016.

\begin{tabular}{cccc}
\hline REGIÃO & \multicolumn{2}{c}{ ORIGEM DOS RECURSOS } & $\mathbf{N}^{\circ}$ DE PROJETOS \\
\hline MDSA & SEAD & \\
Norte & 121 & 3 & 124 \\
Nordeste & 399 & 4 & 403 \\
Sudeste & 169 & - & 169 \\
Sul & 57 & 8 & 65 \\
Centro-Oeste & 79 & 5 & 84 \\
Total & 825 & 20 & 845 \\
\hline
\end{tabular}

Fonte CONAB (2017). Organização pelos próprios autores (2019).

Na medida em que a região Nordeste ganha destaque na distribuição de projetos do PAA e nos investimentos de recursos orçamentários, entende-se que essa política pública se configura como uma medida importante para promover o melhoramento e a expansão da agricultura familiar e fortalecimento das organizações associativas/cooperativas.

\section{A territorialização do PAA na região do Baixo Amazonas: o caso da AACEPPAMO em Óbidos/PA}

A estrutura socioeconômica do município de Óbidos está baseada na agropecuária, agricultura de subsistência, extrativismo vegetal e animal, tendo como principal fator de rentabilidade para o município a pesca. Pelo seu traçado urbano e suas edificações de inspiração lusitana, é considerada a cidade mais portuguesa na linha do equador. Óbidos a saber é uma cidade pródiga em eventos, são realizados famosos festivais no decorrer do ano, como o Festival de Jaraqui, durante o mês de junho, que é o mais conhecido, reunindo milhares de pessoas, que recolhem o saboroso peixe do Amazonas, para em seguida saboreá-lo sob as mais variadas modalidades culinárias (FAPESPA, 2016).

As comunidades também realizam suas festas. Em Andirobal, no mês de março, há o Festival da Castanha; em agosto é realizado o Festival do Acari, no Distrito Flexal. Ocorrem também o Festival da Mandioca e o Festival de Tucunaré, saboroso peixe do Amazonas, que é realizado em setembro, na comunidade de 
Curumú. Outros eventos estão despontando no Município, como a pesca esportiva e as trilhas (feitas por jipeiros, que saem de Santarém).

A localização atual do município de Óbidos é de cunho estratégico, pois a ações e a presença dos colonizadores portugueses demandaram a construção de fortalezas, arquiteturas e monumentos históricos como medida de proteção e defesa do território pelos portugueses. Para a Fapespa (2016), o lugar escolhido para a fixação foi às margens do rio Amazonas, na parte em que ele apresenta um estreitamento considerável. Tanto a boa localização, como o fato de poder desenvolver a catequese no lugar, foram os fatores que contribuíram para a fixação da sede naquele local.

O município de Óbidos pertence à mesorregião do Baixo Amazonas e microrregião Óbidos. Ao Norte, Óbidos faz limite com o município de Oriximiná, a Leste com Almeirim, Alenquer e Curuá; ao Sul, com Santarém e a Oeste com Juruti e Oriximiná. A mesorregião do Baixo Amazonas é uma das seis mesorregiões do Estado paraense, composto pela união dos municípios que fomentam a economia do Estado: Almeirim, Prainha, Monte Alegre, Santarém, Alenquer, Curuá, Faro, Terra Santa, Óbidos, Oriximiná, Juruti, Belterra, cujo potencial do patrimônio natural e cultural tem se colocado como desafio para o desenvolvimento da agricultura familiar, em decorrência das profundas modificações que vem acontecendo no território com a chegada do agronegócio e da extração mineral.

A finalidade de tais projetos, programas e planos pensados para a Amazônia, objetivam promover o crescimento econômico dos agentes hegemônicos voltado para a escala-mundo e tende a modificar a lógica dos lugares e as territorialidades dos diversos povos que habitam o espaço amazônico.

O Baixo Amazonas é considerado estratégico nos Planos atuais de Integração subordinada da Amazônia. Nesta região, os agentes que hegemonizam os cenários de disputas por territórios e os recursos naturais, são as grandes corporações do agronegócio, cercadas pelas empresas que controlam as construções de grandes obras de infraestruturas na Amazônia.

\subsection{O PAA no município de Óbidos}

A partir do ano 2000, inúmeras políticas públicas promoveram qualidade de vida dos trabalhadores e trabalhadoras do campo, principalmente as voltadas para a agricultura familiar. Com a institucionalização do Programa de Aquisição de Alimentos (PAA) e a obrigatoriedade de cerca de 30\% do Programa Nacional de Alimentação Escolar (PNAE) pelo Governo Federal, a agricultura familiar ganhou maior notoriedade e valorização no meio rural. Ambas as políticas públicas, representam a inclusão dos sujeitos do campo nos mercados local e nacional, gerando ocupação de trabalho e renda para muitas unidades familiares e fazendo com que permaneçam em suas terras produzindo, garantindo assim, a sua reprodução social nos seus respectivos territórios de vida.

Em 2017, O PAA experimentou uma redução orçamentária de $66 \%$. Esse programa garante aos produtos da agricultura familiar o acesso aos mercados institucionais e representa uma das principais fontes de financiamento para o setor. Para 2018, a previsão de cortes no Programa é ainda mais severa, indicando uma clara intenção de torná-lo inoperante. Segundo o Projeto de Lei de Diretrizes 
Orçamentária (PLDO) daquele ano, estavam previstos apenas $\mathrm{R} \$ 750$ mil contra $\mathrm{R} \$$ 330 milhões destinados em 2017 ao PAA.

Apesar dos cortes orçamentários efetuados no programa, no município de Óbidos, a atuação do PAA pela AACEPPAMO vem crescendo gradativamente e contribuído com o aumento da quantidade de pescado entregue (Gráfico 2), correspondente aos anos 2010 a 2016.

Gráfico 2 - Evolução do valor do pescado entregue da AACEPPAMO nos anos de 2010-2016.

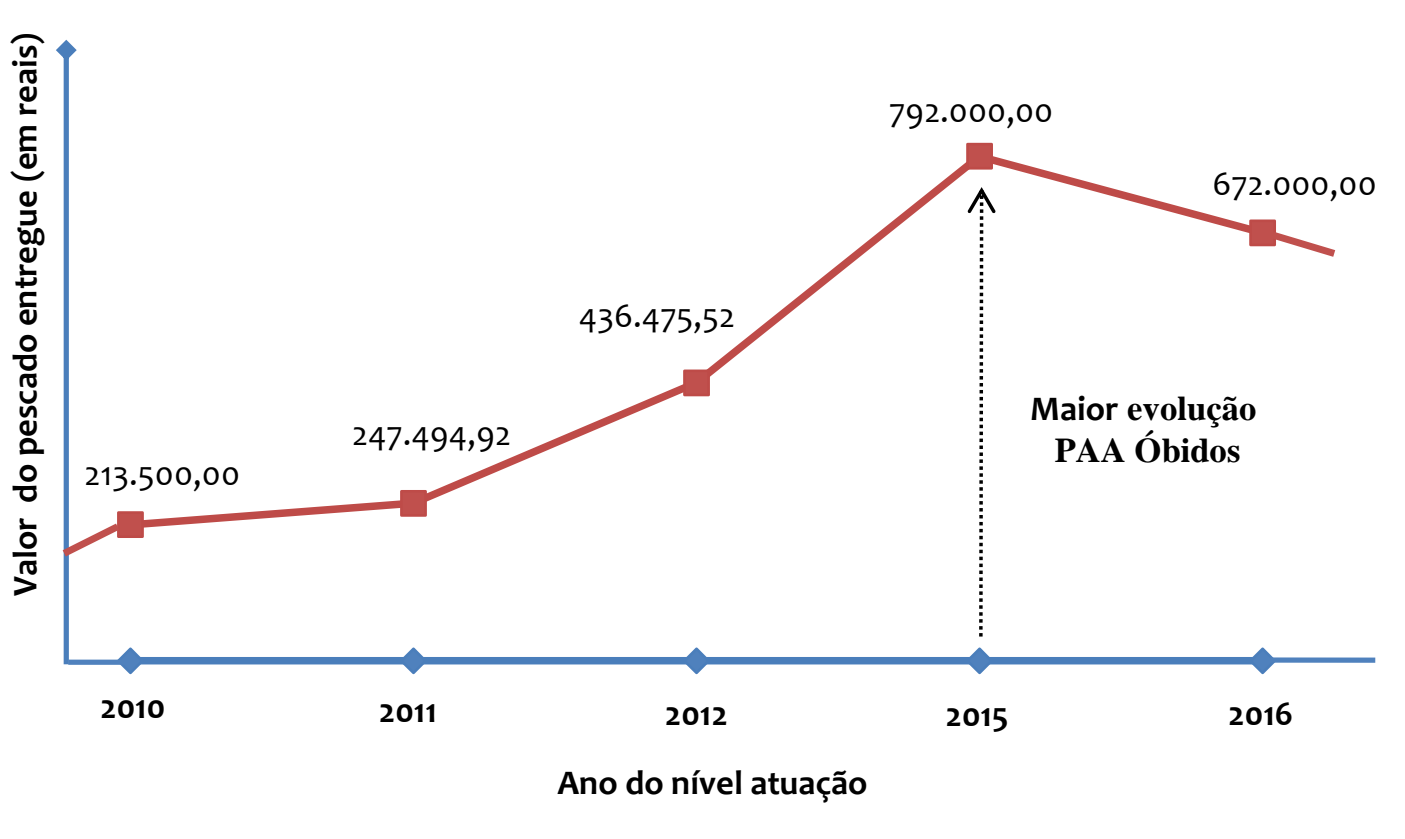

Fonte: CONAB (2017). Elaborado pelos próprios autores (2018).

O demonstrativo manifestado pela evolução da AACEPPAMO no período de 2010 a 2016, observa-se um crescimento da entrega de pescado no ano de 2015 e do nível de atuação da associação nesse período, tendo uma queda no ano de 2016. Durante as pesquisas de campo, constatou-se que essa queda se deu em razão de problemas burocráticos, em virtude do não cadastramento de 8 DAPs no sistema da CONAB. Para que não houvesse atraso no processo, a proposta foi apresentada sem as 8 DAPs que estavam enfrentando problemas, essa situação diminuiu a entrega de pescado geral da associação no ano de 2016.

3.2 AACEPPAMO: Origem, desafios e características

A Associação Agroextrativista dos Pescadores e Pescadoras do Município de Óbidos (ACEPPAMO), objeto desta pesquisa ${ }^{2}$, é constituída pela união e

\footnotetext{
${ }^{2}$ Fundada no dia 18 de agosto de 2006, é uma associação civil de direitos privados, sem fins lucrativos, om sede administrativa provisória, à Rua Antônio Brito de Sousa, 502, bairro de Santa Terezinha, município de Óbidos, mesorregião do Baixo Amazonas no Estado do Pará.
} 
solidariedade de pescadores e pescadoras residentes na área urbana e rural do município, cuja atividade econômica é a pesca artesanal.

Surgiu primeiramente da ideia de 18 pessoas que na ocasião de uma reunião de assuntos de seus interesses, no prédio da Secretaria de Agricultura e Abastecimento do Município de Óbidos, tiveram a ideia de criação de uma associação. A partir de então, organizaram uma assembleia improvisada para definir uma comissão, onde o Sr. João Lessa, morador do município, foi o escolhido para presidir a mais nova associação.

Sendo assim, no dia 18 de agosto de 2006, na residência do Sr. João Lessa da Silva, localizado na rua Antônio Brito de Sousa, $n^{\circ}$ 502, objetivando escolher o nome para a associação. Após votação, decidido em Assembleia Geral, foi eleita a primeira diretoria da referida associação, composta por 1 Presidente, 1 vice-presidente, $1^{\text {a }}$ e $2^{\text {a }}$ secretárias, $1^{\circ}$ tesoureiro e um conselho fiscal e o nome escolhido foi: Associação Agroextrativista dos Pescadores e Pescadoras do Município de Óbidos (AACEPPAMO), cujo nome permanece até os dias atuais.

Além de está presente representantes políticos municipais, estiveram presentes para a fundação da associação, 28 pescadores artesanais residentes da zona urbana e rural do município. Nesse encontro, discutiam sobre a significância de criar uma organização e de como seria de suma importância trabalhar coletivamente, possibilitando que esses sujeitos se recriassem socialmente nos seus territórios vividos.

Os desafios eram grandes e as oportunidades também, mas os associados aprenderam a trabalhar em grupo, mantendo uma relação de parceria. A associação prosperou a cada dia, e com isso, aumentavam o número de interessados em fazer parte da mais nova associação. Com esse aumento, o lugar das reuniões não comportava mais todos os associados. Assim, foi preciso ir em busca de outro ambiente que pudesse alocar todos os interessados, ambiente que pudesse explorar ideias para o crescimento da associação, de forma adequada e eficaz.

As reuniões passaram a ocorrer na Pastoral da Criança. Devido às questões burocráticas, o andamento das atividades do projeto PAA só iniciou suas práticas realmente no ano de 2008, gerido e presidido pelo Sr. João Lessa, que permaneceu no cargo de presidente da associação até o fim do ano de 2012, quando então houve uma nova assembleia culminando numa nova diretoria. A nova eleição aconteceu precisamente no dia 13 de agosto de 2012, sendo escolhido como presidente 0 senhor Osvaldo Procópio e como vice o Sr. Rizaldo Luiz vieira, assumindo o cargo no dia 18 de agosto de 2012.

Por se tratar de uma sociedade associativa possui uma legislação própria (regulamentadas tanto na Constituição Federal, quanto no Novo Código Civil) e uma estrutura organizacional diferente da maioria das sociedades comerciais, possui presidente, vice-presidente, tesoureiro, vice - tesoureiro e conselheiro fiscal e o órgão máximo, que é a Assembleia Geral dos Associados, regida por uma lei especifica, a Lei 10.406/2002 de 10 de Janeiro de 2002.

Atualmente, a AACEPPAMO conta com 84 sócios cadastrados, (40\% são mulheres) e todos fazem parte da Colônia de Pescadores e Pescadoras Artesanais Z19 de Óbidos, situado na rua Almirante Barroso, $n^{\circ} 13$, Centro, local atual de suas reuniões periódicas dos pescadores. Suas principais atividades econômicas, sempre estiveram voltadas para a pesca artesanal e a comercialização das diversas 
variedades de pescados (aracu, curimatã, dourado, matrinchã, pacu, pescada, sarda e surubim).

Com sua nova gestão e uma visão completamente voltada para o desenvolvimento, a associação no decorrer dos anos, ganhou impulso no seu progresso, com a criação de uma nova metodologia voltada para a maximização dos resultados, numa perspectiva sustentável, mas sempre voltado para o desenvolvimento sustentável. De acordo com Osvaldo Procópio Soares, presidente da AACEPPAMO, o objetivo proposto a partir da atuação da AACEPPAMO assegura que:

A AACEPPAMO tem o objetivo de contribuir para $o$ pleno desenvolvimento e crescimento socioeconômico das pessoas que vivem em Óbidos, gerando emprego e renda para as famílias dos pescadores e pescadoras. Desde que ela foi fundada em 18/08/2006, tem sido um prazer de ver as famílias recebendo os pescados pela Pastoral da Criança, é uma satisfação muito grande (SOARES, 2018b, n.p.).

Essa ação geradora de emprego e renda desenvolvida pela AACEPPAMO é cristalizada nas unidades familiares dos pescadores e pescadoras. Em entrevista com Josilene Barbosa Vieira (2018), uma beneficiária do PAA através da AACEPPAMO, ressalta que há mais ou menos 4 anos recebe peixe da AACEPPAMO e que o pescado recebido é bem conservado e tem melhorado a alimentação, além de suprir as necessidades de sua família por média de uma semana. Isso comprova que, o associativismo é uma forma de organização social que além de gerar renda aos pescadores sócios que participam do PAA, garantem alimentos saudáveis e nutritivos a populações de baixa vulnerabilidade social.

A partir de então, gradativamente, o processo foi se expandindo de forma sincronizada, e a cada ano vem se adequando às normas legais, proporcionando o que de fato é o propósito da associação, ou seja, estimular a produção pesqueira, no intuito de beneficiar a inúmeras famílias da zona urbana e rural do município, no fornecimento de alimentos e também como fonte de renda, obtida através da comercialização do pescado para o Governo Federal.

3.3 Etapas de entrega produção pesqueira da AACEPPAMO para as famílias beneficiárias

Antes da entrega do pescado às famílias beneficiárias é construído um cronograma pela AACEPPAMO em conjunto com a Coordenação da Pastoral da Criança, líderes de comunidades, representante da EMATER e da Secretaria Municipal de Abastecimento e Agricultura (SEMAB) e Secretaria Municipal de Assistência Social (SEMAS).

Nessa reunião, não fica definido a data exata para a pesca, mas todos ficam de sobreavisos. Segundo o presidente da AACEPPAMO, Sr. Osvaldo Procópio Soares (2018, n.p), "tudo começa quando algum pescador avisa que já está dando peixe, a partir daí se organizam e definem a data de entrega que é sempre $2^{\mathrm{a}}, 4^{\mathrm{a}}$ e $6^{\mathrm{a}}$ feiras". A entrega só acontece nos outros dias da semana, quando se tem muito peixe e não conseguem entregar todo o pescado no dia agendado. 
Esse cronograma é realizado sempre no início de agosto, período que começa a piracema ${ }^{3}$ que vai de agosto a início de novembro quando começa o período do defeso ${ }^{4}$, e os pescadores são divididos em três grupos. A entrega do pescado (Figura 1) é sempre realizada no período da piracema, mas quando os pescadores não conseguem entregar sua cota de pescado no prazo estipulado na proposta, é feito um pedido de prorrogação pela organização fornecedora, através de ofício à $C O N A B$, justificando o pleito com antecedência mínima de 30 (trinta dias) antes do vencimento.

De posse do cronograma, a coordenação da Pastoral da Criança, reúne-se com as lideranças comunitárias e define os dias que cada paróquia irá receber o pescado, assim como os horários.

Figura 1 - Processo de entrega do pescado pela AACEPPAMO.

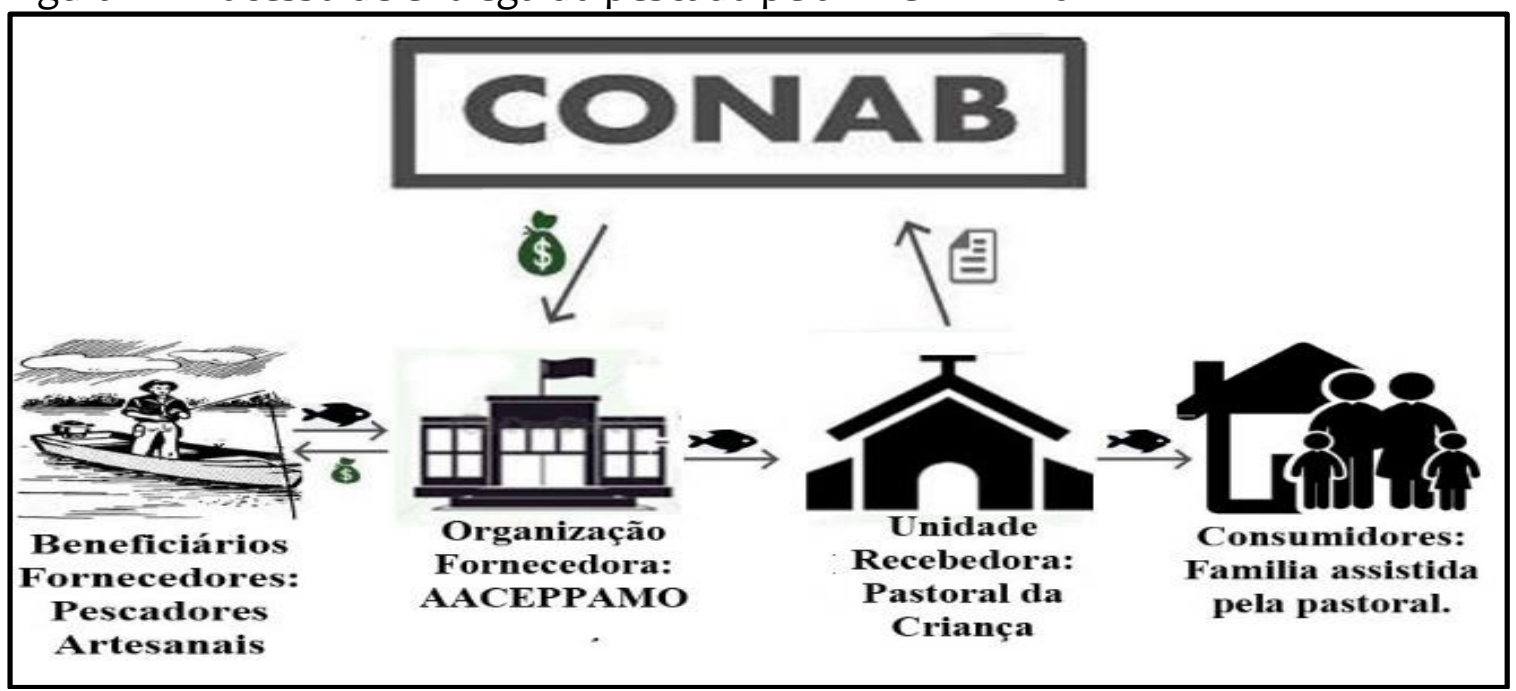

Fonte: CONAB (2017). Adaptado: BRITO, E. (2018).

Quando os pescadores chegam com o produto, tudo é entregue ao presidente da AACEPPAMO que realiza o peso e anotações no recibo de venda de peixe (Figura 2), discriminando o tipo, o preço e total em quilos, na presença de representantes da Pastoral da Criança, representantes da EMATER, SEMAB e pescadores.

Após o processo de pesagem o pescado é entregue para a Coordenação da Pastoral da Criança. No mesmo momento, todo o pescado é encaixotado e levado para o caminhão frigorifico da Colônia Z-19 que já fica aguardando para fazer a entrega nas comunidades atendidas.

A entrega do pescado é acompanhada pela coordenadora diocesana, representantes da EMATER, SEMAB e líderes de comunidades e por vezes, de

${ }^{3}$ É o movimento migratório de peixes em direção às nascentes do rio para reproduzir.

4 No período da piracema os peixes entram no período do "defeso" ou seja, de proibição da pesca. Em quase todos os estados brasileiros o período de defeso começa no dia $1^{\circ}$ de novembro e termina no dia 28 de fevereiro do ano seguinte. 
Territorialização da política pública do PAA e o caso da AACEPPAMO, município de Óbidos, Amazônia Paraense

técnicos da CONAB (Figura 3), para que posteriormente, possam ser redistribuídos para as famílias que são contempladas com o produto.

Figura 2 e 3 - Momentos de entrega e recebimento do pescado pela AACEPPAMO.

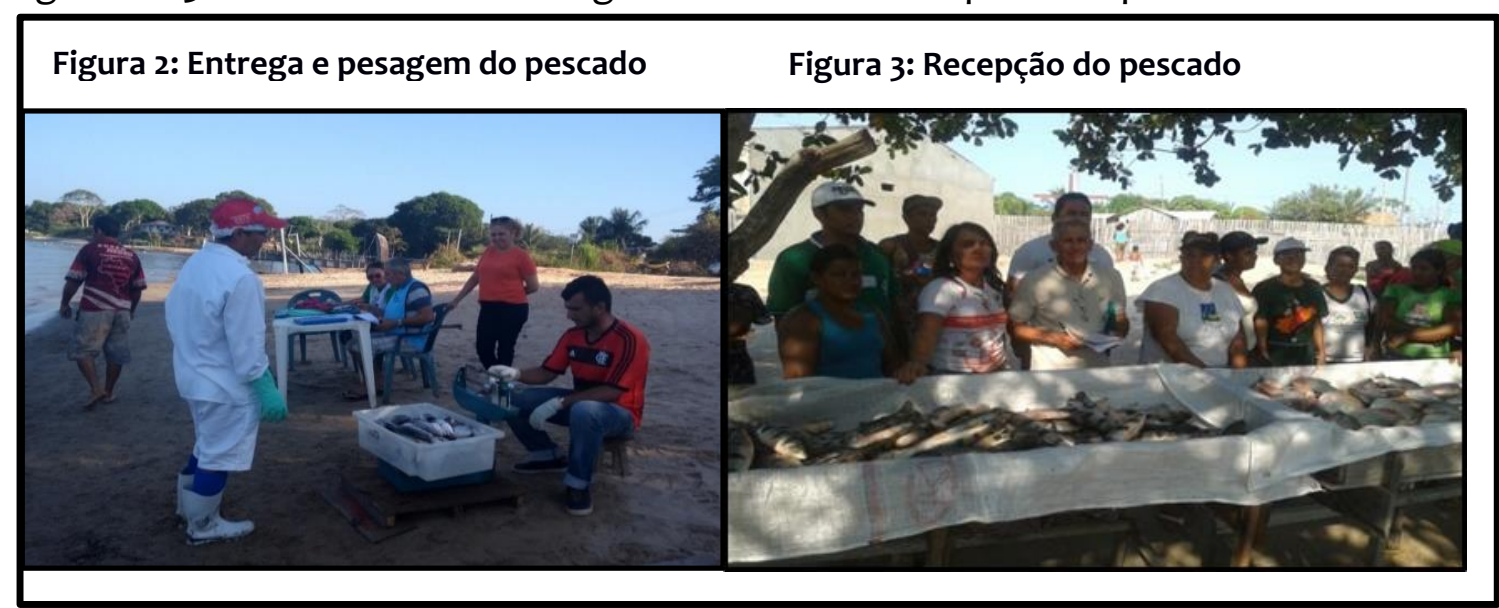

Fonte: Trabalho de Campo. Foto: BRITO, E. (2018).

Fonte: Acervo da Pastoral da Criança (2015).

A entrega do pescado pela AACEPPAMO à Pastoral Sempre inicia das comunidades mais distantes para as mais próximas. Nesses dias, às 6 horas a equipe da Pastoral coordenadora diocesana e presidente da AACEPPAMO se dirigem ao Porto do Matadouro, como é chamado o lugar onde os pescadores estão aguardando.

Figura 4 e 5 - Momentos de pesagem, carregamento e distribuição do pescado nas comunidades.

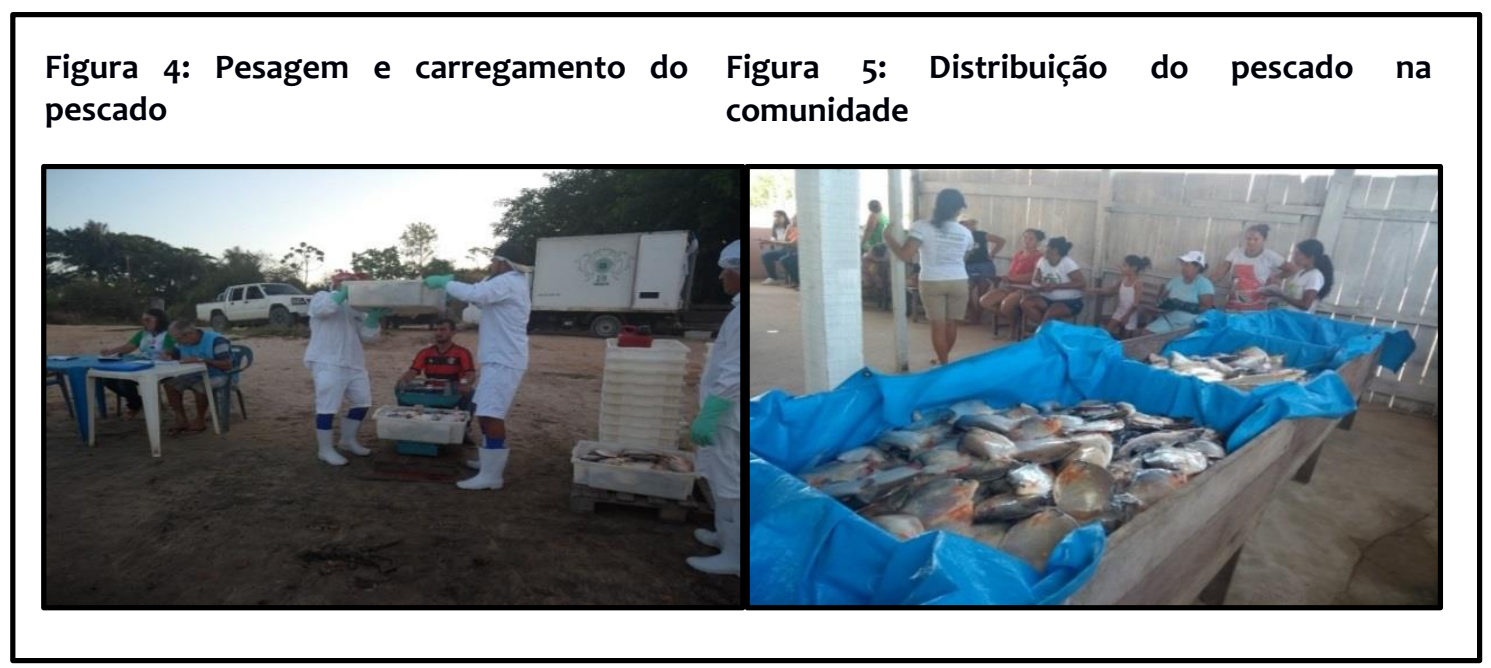

Fonte: Trabalho de Campo. Foto: BRITO, E. (2018).

Observa-se toda uma dinâmica de organização por parte dos pescadores para receber a equipe da AACEPPAMO e da Pastoral da Criança. Nota-se no momento de pesagem, anotação e carregamento dos caminhões (Figura 4) que distribuem o pescado nas comunidades das paróquias da diocese de Óbidos. 
Os peixes são armazenados no caminhão da Colônia de Pescadoras e Pescadoras (Z-19) e são levados para as comunidades destinatárias (Figura 5). Algumas comunidades rurais atendidas pela AACEPPAMO solicitam que o pescado seja enviado por via fluvial (barcos) no Porto do Matadouro. Em entrevista Ana Marialva Soares (2018), coordenadora da paróquia São Martinho de Lima, afirma que:

\begin{abstract}
A entrega aonde os pescadores estão lá na praia. Nós da pastoral (os coordenadores) vamos pra lá 6 horas da manhã e os pescadores já estão nos esperando. Então o peixe é pesado na nossa presença pelo presidente da associação e depois armazenado no caminhão da Z-19. O caminhão mais cedo que chega na comunidade é mais ou menos as nove horas. Abastecem a comunidade São José Operário. Depois abastece Nossa Senhora do Perpetuo Socorro (próximo do São Jose Operário). O caminhão volta para abastecer e volta para as outras comunidades para encher as pasquetas, isso lá pelas 10:30 e 11 horas (SOARES, 2018a, n.p.).
\end{abstract}

Enquanto isso, as lideranças da Pastoral da Criança e das comunidades estão distribuindo as senhas para as famílias que fazem parte da pastoral e organizando as famílias no local de distribuição. É notável que durante a distribuição do pescado compareçam no local de distribuição famílias que não são atendidas pela Pastoral da Criança, mas que sempre recebem pescado da AACEPPAMO, embora em quantidade menor.

\title{
3.4 Distribuição da entrega do pescado pela AACEPPAMO
}

No município de Óbidos, a AACEPPAMO possui um papel e uma função preponderante no que tange à sua territorialização e distribuição do pescado em várias localidades (Tabela 3), áreas urbanas e rurais. Atende 3 paróquias em Óbidos: Paróquia de São Martinho de Lima, Paróquia de Nossa Senhora Sant'Ana e Paróquia de São Francisco e Santa Clara (paróquias unificadas).

Tabela 3 -Distribuição do pescado nas localidades pela AACEPPAMO, 2018.

$\begin{array}{llll}\text { Paróquias } & \text { Comunidades } & \text { Líderes } & \text { Famílias }\end{array}$

\begin{tabular}{c|c|c|c|c}
\hline São Martinho de Lima & 10 & 49 & 382 & 492 \\
\hline Nossa Senhora Sant'Ana & 7 & 41 & 309 & 414 \\
\hline São Francisco e Santa Clara & 8 & 52 & 435 & 574 \\
\hline TOTAL & $\mathbf{2 5}$ & $\mathbf{1 4 2}$ & $\mathbf{1 1 2 6}$ & $\mathbf{1 4 8 0}$ \\
\hline
\end{tabular}

Fonte: Trabalho de campo (2018). Elaborado pelos próprios autores (2019).

As 10 comunidades da paróquia de São Martinho de Lima são distribuídas em 5 na zona urbana e 5 na zona rural. Na zona urbana estão: Santa Terezinha, Cristo é o Senhor, Rainha da Paz, Nossa Senhora do Perpétuo Socorro e São José Operário. Cada comunidade tem uma igreja com o santo e com o nome da mesma comunidade. O local de entrega do pescado nessas comunidades é ao lado do "Clipe" (barracão) de cada Igreja, com exceção da comunidade Nossa Senhora do Perpétuo Socorro, por ainda não ter igreja, é distribuído na creche que fica do lado do barracão paroquial. 
$\mathrm{Na}$ zona rural, localizam-se as comunidades: Arapucu, Curumum, Boa Esperança, Pororoca e Campina. As comunidades de Arapacu e Curumum veem buscar de barco o pescado, enquanto que nas comunidades Pororoca e Campina, o caminhão da Z-19 que transporta o peixe. A comunidade Boa Esperança, por ser uma comunidade com grande abundância de peixe, não recebe.

Na paróquia de Senhora Sant'Ana a entrega é feita através de barco e carro da Colônia Z-19. Na zona urbana existem cinco comunidades: Nossa Senhora de Fátima (igreja com o santo do mesmo nome), Nossa senhora de Lourdes (igreja com o santo do mesmo nome), Bairro da Cidade Nova (igreja com o santo Sagrado Coração de Jesus), Bela Vista (igreja com o santo São Pedro) e Adonias Silva que é um residencial e não possui igreja. Na zona rural existem as seguintes comunidades: Maria Tereza (igreja de São Francisco de Assis), Igarapé do Parú (igreja de São Sebastião).

A paróquia de São Francisco e Santa Clara (paróquias unificadas), são comunidades distantes do centro da cidade e o acesso é por via terrestre. Na zona urbana dessas paróquias existem as paróquias de São Francisco, Santo Antônio, São Lázaro (com igreja e santo do mesmo nome da comunidade). Na zona rural existem mais 5 comunidades: Fuzil, Vila Liberdade, Pará da Nova Bela Vista, Cuecé, São José e Silêncio. As 3 últimas recebem o pescado em bajaras no Porto do Matadouro.

Além das paróquias de Óbidos, a AACEPPAMO atende na área urbana de Óbidos, como no Hospital Municipal, a Fazenda da Esperança vinculada à Diocese de Óbidos, três Secretarias Paroquiais, a Cúria Diocesana, num total de aproximadamente 400 pessoas.

Em Óbidos, a territorialização dessa política pública modifica o panorama socioespacial devido ao grande nível de abrangência do PAA nas múltiplas territorialidades. Além do mais, a AACEPPAMO vem contribuindo com a subsistência e a renda de muitas famílias. O mapa mostra a distribuição geográfica dos pontos de entrega de pescado pela AACEPPAMO (Mapa 2) de acordo com as zonas paroquiais em que estão incluídas as comunidades.

Mapa 2 - Mapa de distribuição de pescado no município de Óbidos, Pará.

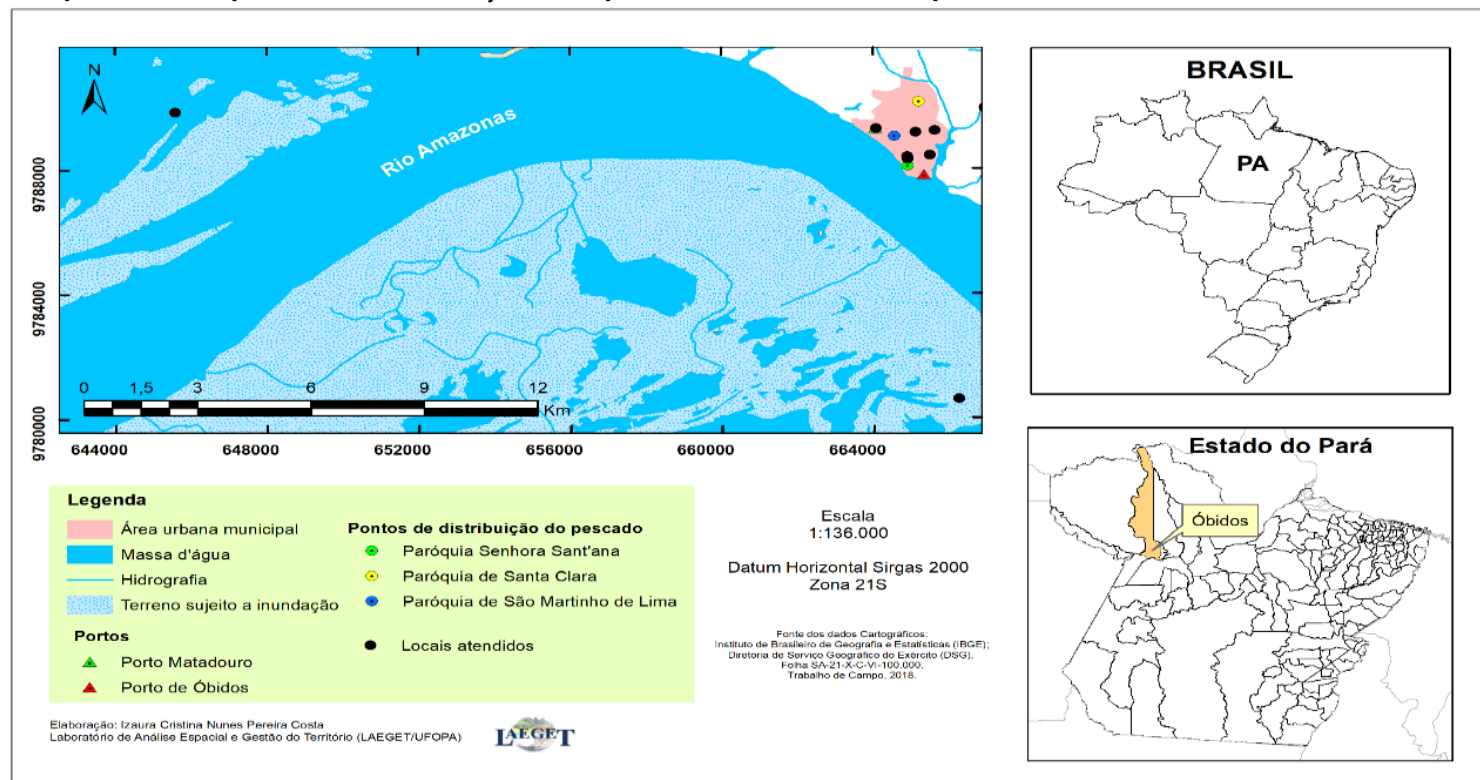

Organização: COSTA, Izaura (2018). Dados: BRITO, Elzamili (2018). 
O caminhão segue para as comunidades paroquiais na segunda feira logo cedo da manhã. A entrega nessas comunidades acontece por volta das ghs, em seguida, o carro da Colônia Z-19 segue para outra comunidade para realizar a distribuição. Após a distribuição em duas comunidades, geralmente o caminhão realiza toda a entrega, fazendo-se necessário retornar ao porto para reabastecer e ir para a próxima comunidade cadastrada do dia. Enche as "pasquetas" e segue com destino para outra comunidade, geralmente essa segunda viagem acontece por volta das 10hs 3omin e 11hs.

O caminhão volta para reabastecer novamente e segue sentido às outras comunidades da mesma paróquia, seguindo o cronograma de entrega feito anteriormente. O pescado é levado sempre na medida, de forma que não falte para as comunidades beneficiárias programadas para receber.

Quem recebe pelo rio, traz seu barco para receber o peixe na praia. Líderes e pessoal de apoio trazem isopor para colocar o pescado depois de pesado. Cada comunidade consegue seu transporte. Quando tem muito peixe eles distribuem de manhã na área urbana e vão para a área rural à tarde.

$A$ cada duas semanas é feito a nota fiscal para pagamento da AACEPPAMO pela CONAB. Nesse período, geralmente já foram entregues de 15 a 20 toneladas de pescado. É confeccionada uma planilha de entrega de pescado e assinada pelo presidente da AACEPPAMO e da coordenação da Pastoral da Criança. Após confeccionar a planilha, o presidente da AACEPPAMO vai na Receita Estadual para extrair a nota fiscal, que posteriormente, é encaminhada via correios para a CONAB, juntamente com o Termo de Recebimento e Aceitabilidade (TRA), Relatório de Entrega e Relatório de Pagamento, para fins de prestação de contas.

A liberação dos recursos acontece por meio de transferência da conta bloqueada (vinculada) para a conta de livre movimentação, mediante autorização formal da CONAB, correspondente à prestação de contas das entregas realizadas, após apresentação dos documentos descritos no parágrafo acima no prazo em média de 40 dias.

\section{Considerações finais}

A territorialização do PAA desempenha grande importância na manutenção da AACEPAMO, posto que apresenta uma política diferenciada em termos de segurança alimentar e de fomento à produção agroextrativista e pesqueira na escala local e regional, envolvendo, de um lado, agricultores familiares que têm dificuldades para comercializar a sua produção, e de outro, as instituições sociais que precisam adquirir produtos no mercado, beneficiando, desta forma, produtores e consumidores.

O modo de vida dos pescadores da AACEPPAMO está intrinsecamente relacionado ao rio e a floresta, como espaços de trabalho das famílias, as quais alternam entre a colheita dos frutos, a captura de animais da floresta e como principal atividade a pesca artesanal no rio Amazonas e seus afluentes. As atividades relacionadas ao agroextrativismo ocupam espaço secundário no trabalho dos

\footnotetext{
${ }^{5}$ Engradado plástico utilizado para carregar peixes.
} 
associados à AACEPPAMO, essa escolha ocorreu por ter sido observado que é na pesca que conseguem o maior retorno financeiro, em especial a partir da parceria com o PAA.

A pesca no rio Amazonas representa para esses pescadores de um lado, uma atividade de extrema relevância, garantido por gerações a manutenção do modo de vida dos pescadores artesanais e das comunidades urbanas e rurais que habitam o município de Óbidos. Por outro lado, é a fonte de alimento que promove segurança alimentar e nutricional das famílias atendidas pela AACEPPAMO e fonte de renda para os pescadores e pescadoras artesanais vinculados a essa associação por meio do PAA.

A atuação do PAA em Óbidos através da AACEPPAMO possui papel destacado quando comparado com os demais municípios do Baixo Amazonas que tem a economia pesqueira como forte atividade econômica devido à diversidade de espécies exploradas, percentual de pescado capturado e pela alta receptividade da população local com este programa.

A expansão da pesca comercial em Óbidos-Pará tem acompanhado o crescimento da Colônia de Pescadoras e Pescadores Artesanais (Z-19) e da AACEPPAMO. Verificou-se que a cada ano vem ocorrendo um aumento de pessoas envolvidas no setor, esses números acompanham o crescimento do número de associados nessas duas entidades pesqueiras daquele município. A partir dos levantamentos em campo, verificou-se também que com a criação da AACEPPAMO e da expansão da Colônia Z-19, ocorreu um crescente esvaziamento da mão de obra na agricultura da várzea.

Constata-se que a territorialização do PAA contribui para a melhoria da renda dos pequenos agricultores/pescadores, provando ser uma modalidade de admirável poder estruturante, uma vez que, através desse mercado institucional a agricultura familiar e a pesca artesanal geram trabalho e renda, dinamizando a economia local, fortalecendo as organizações econômicas de produção familiar, contribuindo para a segurança alimentar, pra conservação do meio ambiente e da manutenção da população no campo.

Dessa forma, o PAA se mostra como um importante instrumento de fortalecimento da política social e econômica da região, que como vimos ainda é deficitário na Região Norte e no Baixo Amazonas. Estudos como este, contribui em visibilizar a melhoria que o programa promove na qualidade de vida dos grupos sociais envolvidos, garantindo a alimentação nutritiva, saudável e digna, bem como, a valorização da pesca artesanal, aproximando por meio da dinâmica dos rios e da floresta amazônica, um arranjo inter organizacional entre Estado, sociedade civil e movimentos sociais da agricultura familiar.

\section{REFERÊNCIAS}

BRASIL. Casa Civil. Decreto $\mathbf{n}^{\circ}$ 7.775, de 4 de julho de 2012 (Regulamenta o art. 19 da Lei $\mathrm{n}^{\circ}$ 10.696, de 2 de julho de 2003, que institui o Programa de Aquisição de Alimentos. Disponível em: http://www.planalto.gov.br/ccivil_03/_Ato20112014/2012/Decreto/D7775.htm. Acesso em: 25 nov. 2018. 
BRASIL. Companhia Nacional de Abastecimento. Compêndio de Estudos CONAB v. 1 Brasília: 2017. Disponível em:

http://www.CONAB.gov.br/conteudos.php?a=1066\&t=1. Acesso em: 26 fev. 2018 .

BRASIL. COMPANHIA NACIONAL DE ABASTECIMENTO. CONAB. Programa de Aquisição de Alimentos (PAA): Resultados das Ações da CONAB em 2014. [s.l.]: Caderno CONAB, 2014.

BRASIL. Companhia Nacional de Abastecimento. Oficina de documentação participativa do Programa de Aquisição de Alimentos da Agricultura Familiar - PAA. Relatório Síntese. CONAB, 2006. Disponível em http://www.CONAB.gov.br/conaweb/agriculturafamiliar/paa_legislacao.I. Acesso em: 12 de agosto de 2017.

BRASIL. Lei $n^{\circ} 11.346$, de 15 de setembro de 2006. Cria o Sistema Nacional de Segurança Alimentar e Nutricional. Diário Oficial da União. Brasília, DF, 18 set. 2006. Seção 1, p. 1-2.

BRASIL. Ministério do Desenvolvimento Agrário. Agricultura familiar no Brasil e o censo agropecuário 2006. Disponível em:

http://portal.mda.gov.br/portal/saf/arquivos/. Acesso em: 13 de ago. 2017.

BRASIL. Ministério do Desenvolvimento Social e Combate à Fome. PAA: 10 anos de aquisição de alimentos. Brasília, 2014.

BRASIL. Resolução n. 39, de 26 de janeiro de 2010. Diário Oficial da União.

Disponível em: www.CONAB.gov.br. Acesso em: 12 ago. 2017.

CORDEIRO, A. Resultados do programa de aquisição de alimentos - PAA: a perspectiva dos beneficiários. Brasília: CONAB, 2007.

FAPESPA. Fundação Amazônia de Amparo a Estudos e Pesquisas. Estatísticas Municipais Paraenses: Óbidos. Belém, 2016.

GUARESCHI, A. A Operacionalização da política de segurança alimentar: O caso do Programa de Aquisição de Alimentos em Tenente Portela, RS. 2010. Dissertação (Mestrado em Desenvolvimento Rural) - Universidade Federal do Rio Grande do Sul, Faculdade de Ciências Econômicas, Porto Alegre, 2010.

HAESBAERT, Rogério. Da desterritorialização á multiterritorialidade. In: Anais do X Encontro de Geógrafos da América Latina. Universidade de São Paulo. 2005.

HONDA, Yohane Figueira; GOMES, Sérgio Castro; CABRAL, Eugênia Rosa. Participação dos produtores familiares no PAA: estratégias de produção e comercialização em área periurbana do município de Ananindeua, PA. In: Revista Cesumar Ciências Humanas e Sociais Aplicadas, v.21, n.1, p. 125-145, jan./jun. 2016. 
KROTH, Darlan Christiano et al. Análise da operacionalização da política de aquisição de alimentos da agricultura familiar por parte dos municípios: o caso do PNAE em três microrregiões do Oeste Catarinense. Redes (Santa Cruz do Sul. Online), v. 24, n. 1, p. 138 -162, janeiro-abril, 2019.

MÜLLER, Ana Luiza, SILVA, Marcelo Kunrath, SCHNEIDER, Sergio. A construção das políticas públicas para a agricultura familiar no Brasil: o Programa de Aquisição de Alimentos. Estudos Sociedade e Agricultura, abril de 2012, vol. 20, n. 1, pp. 106-138.

RAFFESTIN. Claude. Por uma geografia do poder. São Paulo: Ática, 1993.

SALGADO, Rafael Junior dos Santos Figueiredo et al. Focalização e Cobertura do Programa de Aquisição de Alimentos (PAA): avaliação de sua eficácia nas regiões brasileiras. Revista de Economia e Sociologia Rural. Piracicaba - SP, Vol. 55, Nº4, p. 661-678, Out/Dez 2017.

SAMBUICHI, Regina Helena Rosa et al. Compras públicas sustentáveis e agricultura familiar: a experiência do Programa de Aquisição de Alimentos (PAA) e do Programa Nacional de Alimentação Escolar (PNAE). In. SAMBUICHI, Regina Helena Rosa [et al.]. Políticas agroambientais e sustentabilidade: desafios, oportunidades e lições aprendidas / organizadores: - Brasília: Ipea, 2014.

SCHMITT, Claudia Job. Aquisição de alimentos da agricultura familiar Integração entre política agrícola e segurança alimentar e nutricional. Revista de Política Agrícola. Ano XIV - N² - Abr./Maio/Jun. 2005.

SEBRAE. Políticas Públicas: conceitos e práticas. Belo Horizonte: [s.n.], 2008.

SOARES, Ana Marialva. Entrevista com a coordenadora da Paróquia São Martinho de Lima. [Entrevista cedida a] Elza Lima de Brito. Óbidos, 15 de junho de 2018a.

SOARES, Osvaldo Procópio. Presidente da AACEPAMO. Entrevista sobre a atuação da AACEPPAMO. [Entrevista cedida a] Elza Lima de Brito. Óbidos, 06 de jul. 2018b.

TEISSERENC, Pierre. Ambientalização e Territorialização: situando o debate no contexto da Amazônia brasileira. In: Revista Antropolítica, n. 29, p. 153-179, 2. sem. 2010.

VEIGA, I.; OLIVEIRA, M.; BENTES, F. Políticas públicas e dinâmicas locais da agricultura familiar no sul e sudeste do Pará. In: TONNEAU, J. P.; SABOURIN, E. (Org.). Agricultura familiar: interação entre políticas públicas e dinâmicas locais: ensinamentos a partir de casos. Porto Alegre: Ed. da UFRGS, 2007.

VIEIRA, Josilene Barbosa. Entrevista sobre a atuação da AACEPPAMO. [Entrevista cedida a] Elza Lima de Brito. Óbidos, 16 de junho de 2018. 
Márcio Júnior Benassuly Barros. Doutor em Geografia. Professor adjunto da Universidade Federal do Oeste do Pará (UFOPA). Líder do Grupo de Pesquisa Políticas Públicas e Dinâmicas Territoriais na Amazônia (GPDAM/UFOPA/CNPQ). E-mail: marcio.barros@ufopa.edu.br

Elzamili Lima Brito. Pedagoga e Bacharel em Gestão Pública pela Universidade Federal do Oeste do Pará (UFOPA). Membro do Grupo de Pesquisa Políticas Públicas e Dinâmicas Territoriais na Amazônia (GPDAM/UFOPA/CNPQ).

E-mail: elzamili.brito@gmail.com

Francilene Sales da Conceição. Doutoranda em Geografia (PPGG/UNIR), Pesquisadora do GP Gestão do Território e Geografia Agrária da Amazônia (GTGA/UNIR) e Pesquisadora do Grupo de Pesquisa Políticas Públicas e Dinâmicas Territoriais na Amazônia (GPDAM/UFOPA/CNPq). E-mail: lenesalesgeo@hotmail.com

Raoni Fernandes Azerêdo. Doutorando em Geografia (UFPB). Professor da Universidade Federal do Oeste do Pará (UFOPA), Campus de Alenquer. E-mail: raoniazeredo@gmail.com

Como citar: BENASSULY BARROS, Márcio Júnior et al. Territorialização da política pública do PAA e o caso da AACEPPAMO, município de Óbidos, Amazônia Paraense. Redes (St. Cruz Sul, Online), Santa Cruz do Sul, v. 25, p. 1603-1627, nov. 2020. ISSN 1982-6745. doi:https://doi.org/10.17058/redes.v25i4.13440.

\section{CONTRIBUIÇÃO DE CADA AUTOR}

a. Fundamentação teórico-conceitual e problematização: Márcio Júnior Benassuly Barros, Elzamili Lima Brito e Raoni Fernandes Azerêdo

b. Pesquisa de dados e análise estatística: Elzamili Lima Brito e Raoni Fernandes Azerêdo

c. Elaboração de figuras e tabelas: Elzamili Lima Brito e Francilene Sales da Conceição

d. Fotos: Elzamili Lima Brito

e. Elaboração e redação do texto: Elzamili Lima Brito, Francilene Sales da Conceição e Raoni Fernandes Azerêdo

f. Seleção das referências bibliográficas: Márcio Júnior Benassuly Barros, Elzamili Lima Brito, Francilene Sales da Conceição e Raoni Fernandes Azerêdo

Fontes de financiamento: 